\title{
Kinesthesia, Empathy, and Related Pleasures: An Inquiry into Audience Experiences of Watching Dance
}

\author{
Matthew Reason and Dee Reynolds
}

D ance is frequently described as being "about" movement. "Dance,"writes Ann Daly, "although it has a visual component, is fundamentally a kinesthetic art" (Daly 1992, 243). Audience experiences of dance can therefore be conceptualized in terms of responses to movement, most prominently in terms of what has been described as "kinesthetic empathy." What does it mean, however, to watch, respond to, or appreciate movement? And how does the historical and theoretical concept of kinesthetic empathy relate to contemporary audiences' articulations of the experience of watching dance?

This article sets out to answer these questions by exploring different kinds of kinesthetic and empathetic responses and pleasures (and indeed displeasures) articulated by spectators of live dance across different styles and contexts. Pleasure is of particular

Dr. Matthew Reason is a senior lecturer in theatre and head of programme for M.A. studies in creative practice at York St. John University, United Kingdom. His work explores themes relating to performance documentation, reflective practice, audience research, theater for young audiences, live art and contemporary performance, and cultural policy. $\mathrm{He}$ is currently working on "Watching Dance: Kinesthetic Empathy," a cross-disciplinary research project funded by the Arts and Humanities Research Council. He is the author of Documentation, Disappearance and the Representation of Live Performance (Palgrave, 2006) and The Young Audience: Exploring and Enbancing Children's Experiences of Theatre (Trentham, 2010). He has also published in a numerous journals, including New Theatre Quarterly, Dance Research Journal, Performance Research, and Studies in Theatre and Performance.

Dee Reynolds is professor of French at the University of Manchester, United Kingdom. She researches on dance history and theory, dance audiences, and comparative aesthetics. She is currently principal investigator on "Watching Dance: Kinesthetic Empathy," funded by the Arts and Humanities Research Council, 2008-201I (<http://www.watchingdance.org〉). She is the author of Rhytbmic Subjects: Uses of Energy in the Dances of Mary Wigman, Martha Graham and Merce Cunningham (Dance Books, 2007) and Symbolist Aesthetics and Early Abstract Art: Sites of Imaginary Space (Cambridge University Press, 1995) and co-editor with Penny Florence of Feminist Subjects, Multi-Media: Cultural Methodologies (Manchester University Press, 1995). Her publications have appeared in numerous journals, including Body and Society, Body Space and Technology Journal, Dance Research and Dance Theatre Journal. 
importance to audience studies because it relates to motivations. Why do people seek out dance performances to watch? What are they looking for in the experience? In this context, we are interested in kinesthetic empathy as a mode of engaging with dance that can give pleasure to spectators and can be a strong motivating factor in why people choose to watch dance. However, we feel that any attempt to define audience responses in terms of preformed concepts of kinesthetic empathy enacts a kind of teleology that also potentially closes down and prejudges possible responses to dance. We are critical of the potential universalism present in conceptualizations of kinesthetic empathy and are interested in how ideas of kinesthetic empathy are relevant to viewers who have different experiences of dance and different motivations.

We are also aware of the current interest in the "mirror neuron" system as a methodology for understanding responses to dance, particularly in terms of the wider context of this research within a cross-disciplinary research project. ${ }^{1}$ However, this paper does not respond to discussion of the mirror neuron system. Nor is it primarily a discussion of kinesthetic empathy in dance history or theory. Instead, it is firmly located within the ethnographic traditions of audience research and driven by extensive primary research material. Qualitative audience research deals with conscious, reflective responses post-performance. Our audience research material has made it possible to identify a range of kinesthetic pleasures that spectators articulate in response to watching live dance. The very breadth of pleasures recorded and presented here is a key point of the paper, which aims to stress that we need to think of kinesthetic responses in the plural rather than the singular. These often involve empathetic experiences but also include kinesthetic responses that are linked with broader aspects of emotion, admiration, escapism, and sensuality, some of which, we will suggest, can be conceptualized with reference to "sympathy" and "contagion."

As a result, this paper is structured through discussion of a series of possibilities, mapping the range of pleasures, motivations, and expectations through which spectators engage with the kinesthetic aspects of dance. Martin Barker's discussion of audiences is useful here: "Being an audience for anything is never a simple or singular process. It is a process that begins in advance of the actual encounter, as people gather knowledge and build expectations. [...] In other words, audiences bring their social and personal histories with them" (Barker 2006, I24; emphasis in the original). We shall refer to pleasures or interpretative "strategies" to designate the instinctive and largely automatic and engrained processes that motivate spectators in their engagement with dance. The plural of "strategies" indicates our interest in describing the multiple and nonhierarchical nature of spectator responses.

\section{Watching Dance-Methodologies}

The research presented in this paper is located within a larger project, "Watching Dance: Kinesthetic Empathy" (<http://www.watchingdance.org $>$ ), that uses audience research and neuroscience to explore how dance spectators respond to and empathize with dance. This is a three-year, multidisciplinary project, involving collaboration across four institutions (Manchester, Glasgow, and York St. John universities and Imperial College London), 
that is funded by the Arts and Humanities Research Council in the United Kingdom. The materials we discuss here draw on the audience research data gathered by this project through a range of qualitative approaches-including interviews, focus groups, and creative techniques - that involved in-depth engagement with relatively small numbers of individuals in order to gain a nuanced and detailed understanding of their experiences and responses to dance performances. One of the primary objectives of all qualitative audience research is to elicit talk from participants, providing circumstances where they can respond to their experiences in their own words and in an open manner (see, for example, Geraghty 1998; Reason 2006; Schoenmakers 1990). In addition, at times we introduced more structured elements, using prepared questions focusing on particular areas of interest, such as music or embodied responses. To date, over 150 spectators have participated in various aspects of the qualitative research, which was carried out in Glasgow and Manchester.

This data was analyzed with the aid of NVivo, using a coding structure that linked phrases and responses according to theme and area of interest. This coding structure was devised from a sample reading of a selection of data and both responded to our own predetermined themes-defined by the project's research questions - and allowed us to bring into focus recurring and often unexpected motifs as they emerged from the material.

All qualitative audience research raises huge methodological questions, which cannot be developed fully here. Key amongst these is what value or credit we invest in participants' expression of their own experiences. Willmar Sauter raises these issues briefly in The Theatrical Event when discussing his own audience research, which took the form of post-performance "theatre talks." Here Sauter observes that in his research he was required to "Take it for granted that the utterances of a participant correspond with the speaker's actual opinion... This is both an empirical and an epistemological problem, which we solved simply by assuming that people mean what they say" (Sauter 2000, 177). We are of course acutely aware that in fact we cannot and do not always say what we mean-or know what we mean - and also conscious that the deconstruction of an easy relationship between language, intention, and meaning was a key critical development of the twentieth century. And yet at the same time, qualitative research with people becomes distorted and perhaps also unethical if we start second guessing and reinterpreting participants' statements - they may have said this, but actually in our superior wisdom we know they meant that. Moreover, engaging people in conversation about their experience of dance is a process whereby that experience is not merely reported but also constructed. In this sense participants mean what they say because the process of talking constructs meaning. We recognize that this construction is contingent, fluid, multiple, and might change according to who they are talking to and over time, but it is nonetheless a significant aspect of their experience. ${ }^{2}$

This paper draws primarily on interview and discussion group material conducted in response to a range of different dance styles and performances, including theater performances by U.K. companies such as George Piper Dances and Scottish Ballet and performances in more controlled "laboratory" circumstances where we presented participants with short pieces choreographed to allow us to explore particular questions or themes. ${ }^{3}$

, 
As this indicates, the issue of what dance is and what kind of dancing is being discussed is a significant implied problematic in any project titled generically "watching dance."

Spectators' perceptions of dance are highly context-specific. In presenting the material below we are predominantly presenting the responses of particular individuals to particular performances at a particular time and place. As far as possible within the confines of a nontechnical paper such as this, these particularities will always be made transparent. This objective is challenging for qualitative research, where the sheer scale of the material makes it difficult to open up the methods and data to public inspection. Instead of allowing readers to make their own analysis and judgments of validity, reports can only provide extracts and fragments of primary material as supporting evidence. As David Silverman writes, "the critical reader is forced to ponder whether the researcher has selected only those fragments of data which support his argument" (Silverman 1993, 162). There are various possible ways to address this difficulty, including the clear articulation of the research approach and of the role of the researcher in producing the material (both provided within this discussion), the linking of quantitative data to the qualitative material, ${ }^{4}$ or the provision of extensive extracts of material rather than short anecdotes (a demand that faces strictures of length and conciseness in printed papers). On the last point, Christine Geraghty notes that with such material "Researchers often emphasize their wish to provide enough of the transcribed material to make it speak beyond their particular use of it" (Geraghty 1998, I48).

We do undertake some process of generalization, of reading out from the particular to the general, partly because such a process is to some extent inevitable as well as useful. We have sought to make connections between the articulations of specific experiences, presented by our research participants, and wider conceptual, theoretical, and historical debates concerning dance studies and kinesthetic experience. We recognize that the material we present will raise for any reader all sorts of other connotations and questionsabout gender, class, cultural capital, language, choreography, and embodiment, among others - that are generated by the complexity and richness of the qualitative data we are discussing. Unable to deal with all these issues in one paper, however, our intention here is more specifically to draw out readings relating to kinesthetic responses. The first stage of this is through setting up the contextual background of kinesthetic empathy.

\section{Empathy, Kinesthesia, and the Idealized Dance Audience}

Both "kinesthesia" and "empathy" are elusive concepts, and while it is beyond the scope of this article to develop a full discussion of these concepts and how they have been used, a brief overview will be useful at this point. Broadly speaking, "kinesthesia" refers to sensations of movement, being derived from the Greek kinein, to move, and aisthesis, sensation. Sensing body position and muscle tension can be considered as integral to kinesthesia, defined as "awareness of the position and movement of the parts of the body by means of sensory organs (proprioceptors) in the muscles and joints"(ODE, 2003). Although the terms "kinesthesia" and "proprioception" are sometimes used interchangeably, a distinction is often made between "proprioception," referring to stimuli from inside the organism, and 
"exteroception," referring to stimuli received from outside the organism. "Kinesthesia" as defined here involves both types of stimuli, and for our purposes it will be considered to include proprioception (see Reynolds 2007). Kinesthesia can be considered as integral to perception, seen as not purely visual but active and multisensory (see, for instance, Gibson 1979, Merleau-Ponty 1962, Berthoz 2000).

"Empathy" is another problematic term; it has many different meanings and has slippery relationships with the term "sympathy" and also with the concept of "emotional contagion." Emotional contagion refers to "catching" and being overpowered by emotions from others, such as crying in response to someone else who is crying (on this topic see, for example, Foster 2008, Gallese 2008, and Stein 1970). Before the English word "empathy" was coined by Edward Titchener to translate the German Einfüblung in 1909 (Titchener 1909), the closest English word was "sympathy." Susan Foster has argued that the eighteenth-century concept of "sympathy," as espoused by David Hume, Adam Smith, and others, evolved into the later concept of empathy as a form of fellow-feeling, which was embodied and predicated on muscular as well as psychic experience (Foster 2010). In contemporary discourse, empathy is frequently viewed as embodied simulation or substitution and sympathy as a response involving feelings. For Bruce McConachie, writing on theater audiences from the perspective of cognitive psychology, empathy means imagining "stepping into an actor/character's shoes," whereas "sympathy involves projecting her or his own beliefs and feelings onto the stage figure" (McConachie 2008, 99). Sympathy involves evaluation of one's position relative to that of the other, while the empathetic process "is mostly automatic," although McConachie argues that "the kind of awareness it produces lodges in memory and is easily brought into consciousness" (27). $\mathrm{He}$ also points out that automatic responses can be the culmination of conscious learning processes and acquisition of cultural norms.

Bringing the two terms "empathy" and "kinesthetic" together, the concept of kinesthetic empathy as it figures in dance studies has been constructed largely through the writings of dance critic John Martin from the I930s through the I960s. Martin himself used a range of terms to describe what we are calling kinesthetic empathy, including "muscular sympathy" and "metakinesis" (Martin 1933, Ir, I3). He also used the term "contagion," referring to "the inherent contagion of bodily movement, which makes the onlooker feel sympathetically in his own musculature the exertions he sees in someone else's musculature" (cited in Foster 2008, 49). For Martin, modern dance was primarily interested in communicating emotional experiences through movement. He argued that "the modern dancer, instead of employing the cumulative sources of academic tradition, cuts through directly to the source of all dancing," which was the connection between movements and emotional states (Martin $1963,13^{8}$ ). There was a strong link between emotion and movement because "the sense organs which report movement and postural change are closely connected with that part of the nervous system which belongs primarily to the inner man where emotions are generated"(Martin 1939, 47). The ideal spectator would respond kinesthetically, experiencing the dance through his or her own sense of movement and postural change-hence Martin's declaration that "the irreducible minimum of equipment demanded of a spectator ... is a kinesthetic sense in working condition" (Martin 
1936/1968, II7) —and this kinesthetic response would trigger a corresponding emotional impact. Martin therefore advised spectators that "It is essential when approaching the dance to carry along the expectation of response to movement and a reliance on the faculty of "inner mimicry"' (Martin r939, 55).

This "inner mimicry" would give spectators the sense that they were actively participating in the dance and directly experiencing both its movements and their associated emotions. Martin suggested that spectators could and should become by-proxy participants as well as observers, a role that was qualitatively different from that of a performer and of a spectator if conceptualized as passive:

We shall cease to be mere spectators and become participants in the movement that is presented to us, and though to all outward appearances we shall be sitting quietly in our chairs, we shall nonetheless be dancing synthetically with all our musculature. Naturally these motor responses are registered by our movementsense receptors, and awaken appropriate emotional associations akin to those which have animated the dancer in the first place. It is the dancer's whole function to lead us into imitating his actions with our faculty for inner mimicry in order that we may experience his feelings. (Martin 1939,53$)^{5}$

This account depends on an unproblematic transition from the visual to the muscular and also from the muscular to the emotional, on the basis that the spectator's emotional associations with movement (arising from paths traced in the muscular system) would be the same as the dancer's:

When we see a human body moving, we see movement which is potentially produced by any human body and therefore by our own ... through kinesthetic sympathy we actually reproduce it vicariously in our present muscular experience and awaken such associational connotations as might have been ours if the original movement had been of our own making. (Martin 1936/1968, II7)

Martin's ideas should be seen in the context of developments in dance, which his criticism both responded to and helped to shape. Dance criticism in its own right, independent of writing on theater or music, came to prominence for the first time with Martin's appointment as dance critic to the New York Times in 1927. At this time, modern dancers were beginning to present "dance recitals," in which dance appeared as an independent art form and was attracting new audiences. The new dance deprived spectators of familiar landmarks in terms of narrative and classical ballet vocabulary, and Martin played a crucial role in providing an alternative paradigm of response that could enable spectators to make sense of this new form. Martin's views have continued to be influential in the field of dance studies. ${ }^{6}$ However, they can be perceived as overly prescriptive and based on universalist assumptions, as is implicit in Martin's unreflective use of the word "we" and the easy slippage from "a human body" to "any human body." Discussing Martin, Susan Foster points out that "Kinesthesia as intertwined with the emotions presumes that all humans share this same connection and that they are all equally moved by the same depictions of human predicament or struggle" (Foster 2008, 52). It is now widely 
recognized that, as Hanna Järvinen points out, "bodies and bodily experience are historically specific rather than universally alike" (Järvinen 2007,145$){ }^{?}$

Martin's ideas construct a sense of what an “ideal" response to a dance performance might be, without reference to what dance scholar Mark Franko has described as "a historical and historically bounded self" (Franko 2002, 53). Dance, under Martin's conceptualization, thereby becomes a closed or "readerly" system whereby the audience's task is that of receiving and accurately (here kinesthetically) decoding the meaning invested in it by the choreographer and dancer. This approach ties kinesthetic empathy to a problematic model of intentionality and also ignores the possibility that different audiences expect and receive different kinds of pleasures from dance, watching with different motivations and interpretative strategies.

Indeed, when looking at the various kinds of data we produced, it became clear that audience members responded in a range of manners, many of which could be described as kinesthetic or empathetic, while others related primarily to the social experience, to musical engagement, or to intellectual reflection. Many, of course, expressed responses that crossed over these different areas and were hard to categorize. In this paper we are focusing explicitly on the kinesthetic experience, considering possibilities of empathetic, sympathetic, and "contagious" responses to watching dance movement. The challenge posed for us was to tease out the differences between these kinds of responses without becoming too simplistic or dogmatic in our use of labels. As our title, "Kinesthesia, Empathy, and Related Pleasures," indicates, we are interested not simply in the degree to which spectators might imaginatively enact the movement observed (which is central both to Martin's “inner mimicry" and to the mirror neuron approach) but also in the myriad ways in which kinesthetic and empathetic responses are connected with spectators' pleasures and motivations.

\section{Cultural Capital and Kinesthetic Responses}

Perhaps the first thing that needs saying is that we identified no universalized or textually determined responses to dance movement. Instead, spectators' responses were often very personal, sometimes idiosyncratic, and influenced by prior experience, expectations, and taste. Here we draw in particular on Pierre Bourdieu's discourse of taste and the concepts of "cultural capital" and "habitus." Habitus can be used to describe the process by which social and economic conditions produce (pre)dispositions in taste. This means that our general disposition to consume and seek exposure to certain kinds of things-whether or not we choose to watch dance, for example-is not random or even necessarily wholly self-aware but instead deeply ingrained into embodied cultural practices (Bourdieu I984, IOI-2).

In this context it was vital in considering what people said about watching dance that we knew the perspectives from which they spoke, including levels of experience in watching dance, of taking dance classes, and dance training, and that we differentiated between different styles of dance. As well as allowing us to group and compare responses according to these factors, this also meant that we were able to construct situations where we were able to discuss with participants performances with which we knew they would

-


be familiar or unfamiliar. For example, for one part of the project we chose to compare responses to ballet and bharatanatyam ${ }^{8}$ because these are discrete styles with well-defined vocabularies, by contrast with contemporary dance, which frequently combines elements of different styles. ${ }^{9}$ Utilizing questionnaires supplemented by responses in the interviews to gather information about personal histories in watching different styles of dance, we classified participants as experienced, intermediate, or novice spectators in each of the two dance types.

It is important to take account of the specific meaning of such categorization within the particular milieus in which the research was taking place - that is, among contemporary audiences in the United Kingdom, specifically Manchester and Glasgow. Participants were recruited by a variety of means. Experienced spectators of ballet and contemporary dance were contacted via questionnaires distributed at dance performances at theaters and via Scottish Ballet. First-time spectators of live dance were recruited via personal networks. Experienced spectators of bharatanatyam, who were more difficult to find, were contacted through specialist organizations such as Dance Iyahami and Milapfest. Complications, however, are inevitable: the category of being a "novice" in watching ballet needs to be understood in a Western context where people have an indirect awareness and knowledge of ballet even if they do not seek out the experience specifically. Ballet was known and identifiable by all the participants in a different way than bharatanatyam. Meanwhile, the levels of expertise among the bharatanatyam spectators were limited by availability of opportunities to see live or recorded performances. ${ }^{10}$

While precise categorization according to experience was problematic, what was noticeable, if not necessarily surprising, was that for some participants their responses were very much influenced by the experiences that they brought to the performance. For example, Rosemary, ${ }^{11}$ a frequent ballet watcher, expressed her love of ballet: "It's just, just so enjoyable, I'm a different person, it's just, I just, I just love it, I just ... it's, it's, it's a therapy, I just, would just like to watch it all afternoon ... I just love it." But she responded very differently to bharatanatyam: "I'm watching, but it's not doing anything, I'm trying to make it tell me something but it's not ..." Or the other way round, Andy, a keen and experienced spectator of bharatanatyam, said of the ballet performance: "I'd say I felt quite numb through it ... I can't think of, I didn't feel any excitement ... or compassion or anything for her at all."

In many ways such responses are to be expected; these were people with preformed tastes who had previously identified and become committed to what they like and rejected what they did not like. What is important to note in this instance is that both Andy and Rosemary expressed engaged, emotional, and often kinesthetic responses (this will be discussed and described in more detail later) to the forms of dance they did like. They therefore had what Martin describes as a "kinesthetic sense in working condition," but this alone is not enough to determine whether a spectator engages kinesthetically in a performance.

Participants' responses, therefore, were often significantly determined not just by the movement itself but also by judgment made according to taste. With ballet, for instance, for some participants it was something about which they had already reached conclusions about liking or disliking: 
Maria: The second piece of dance was a ballet piece, obviously, quite elegant and relaxing to me. Although she was very, very good, to me [it was] a lot less engaging, because I thought this sort of stuff is more boring to me.

The prior judgement expressed here-the dance is dismissed as boring immediately on recognition-almost dictates that the spectator is unable to see anything more of the performance; in the interview she certainly struggled to say anything other than that it was ballet and that it was boring. This clearly affirmed the hugely significant maxim articulated by Pierre Bourdieu that "the capacity to see is a function of knowledge": "A work of art has meaning and interest only for someone who possesses the cultural competence, that is, the code, into which it is encoded. ... A beholder who lacks the specific code feels lost in a chaos of sounds and rhythms, colours and lines, without rhyme or reason" (1984, 3). Indeed, in many instances we had spectators reporting that lack of familiarity with the dance style or the music or the movements made it extremely difficult for them to remember details about the performance. For example, Bita talking about ballet music: "Because you know I don't understand anything about that, that's why ... I couldn't register the music, what type of music it was." Or Laura on bharatanatyam: "I suppose I've never really seen a huge amount of Indian dancing. It was totally different from anything you would imagine to see, it was kind of ... I don't know, I'm just trying to think, I need to kind of think about things a little bit more exactly, about the performance again." For some spectators, therefore, lack of familiarity caused distance and an inability to connect with or even see the movements being performed. One participant described the result as a kind of "voyeurism," watching something that might be visually splendid ("a feast for the eyes") but that ultimately is not emotionally connecting. While for some participants lack of knowledge and lack of understanding led directly to a lack of enjoyment, an equal number of spectators exhibited an openness to new kinds of dance, although part of this openness was awareness of a lack of competency. Abhishek, for example, reported being mesmerized by the section of ballet on pointe and being aware that although enjoying it, a lack of familiarity caused a kind of distance:

Abhishek: Definitely I'm impressed. I wish to see more of ballet, so that I can get involved. I realise I am not involving myself because there was two things going on in my mind. One is enjoying at the same time I was thinking: how did she do it?

Interviewer: And that's particularly because it's new to you?

Abhishek: It's new to me. The next time I watch ballet will be much more smoother.

"Smoother" here is an interesting word, which can be interpreted as suggesting that lack of knowledge made the experience somewhat disjointed or distanced-not unlike, perhaps, reading in a foreign language without adequate competency. In contrast, Abhishek suggests that the experienced spectator has a smooth and unencumbered experience.

While there is not space in this context to go into a detailed discussion of concepts of cultural capital, our conclusion is that what spectators bring to the performance--in 
terms of familiarity, expectations, and taste-must never be forgotten, and we must think about their responses to specific dance styles and specific movements experienced in specific social contexts.

\section{Admiration of Virtuosity}

One of the most prominently recurring themes in participants' responses to dance was what we have termed "admiration of virtuosity."This was most particularly articulated in responses to ballet performances. For example, Samantha, an inexperienced dance watcher, commented on ballet: "I think I was sort of amazed by her and what she could do ... Just sort of thinking a lot about how she was able to do what she was doing and how skilful that was." Similarly Tom, a frequent ballet watcher, said: "The fact that somebody can do these things and not fall over when on their points ... to me is very impressive. I think that's the main thing I see in classical ballet."

The audience's admiration of the virtuosity of the performers, therefore, was connected to many elements and responses, the first being that of amazement, of wondering "how did she manage to do all these postures" (Abhishek, inexperienced spectator). Present for both experienced and inexperienced spectators, for many people this "wow" factor clearly never entirely goes away. Inevitably, however, there is a degree to which the virtuosity has to be apparent to be admired. For instance, some inexperienced dance watchers criticized what they saw as lack of virtuosity in a bharatanatyam performance:

Gina: The thing which I actually thought afterwards [was that] it didn't require as much skill as a ballet. And I feel horrible because obviously it requires, again, skill and practice, but I just couldn't see it.

It is worth briefly noting the difference here between admiration of virtuosity and admiration of skill or craft. The virtuosic performance elicits a "wow" factor, often linked to a very embodied engagement, and for some spectators it is this thrill that forms a very strong drive and reward in watching dance. In contrast, recognition of skill or craft requires a greater learned appreciation of the sometimes invisible work that goes into a performance.

One result of this is that to some extent it equates dance to a series of perfectly executed movements and sheer athleticism and reduces it to a high-wire act. Here part of the audience's interest becomes that of spectacle, the thrill of the live performance being that of witnessing in person whether the movements can be pulled off without mistakes. As one participant noted, "I was looking for her to make a mistake but she didn't."This element of liveness in the enjoyment of virtuosity is also present in the vicarious risk that is invested in live broadcast television but declared absent from pre-recorded media. It can, however, be critiqued as voyeuristic, as Glenn Gould (a pianist who famously stopped performing live at the height of his career in 1964) writes: "I have always had grave misgivings about the motives of people who go to concerts, live theatre, whatever" (Gould 1984, 453).

Part of Gould's fear was that inevitably admiration for virtuosity focuses our attention 
on the most obviously fancy bits, which in dance might be the highest leaps and most daring movements. Interestingly, a paper by Calvo-Merino et al. that describes research designed to explore dance audiences' aesthetic likes/dislikes through use of brain scanning concluded that there was greatest preference for movements that involved "significant displacement of the body in space (e.g., jumping)" in contrast to smaller, more isolated gestures or movements without a vertical element. They then note that "Choreographers could use this information to "neurotarget" their choreography" (Calvo-Merino et al. 2008, 918).

For some of our participants this spectacle was what they were looking for in dance. For others, technical skill was the source of a cooler admiration-"she was dancing her dance and doing it very well and you know, correctly, I'm sure, but, it didn't move me"or of a purely visual pleasure. However, there were a number of areas where we felt that admiration for virtuosity moved into more complex and perhaps empathetic elements. The first were occasions when what was often a detached or cool admiration of skill became a "hotter" or more emotional response. For example, Rosemary observed: "Just the fact that a human body can do that, you know, and so effortlessly and so beautifully, it just makes me feel good."This response to movement in terms of its effortlessness, grace, or flow often resulted in individuals describing how it made them feel happy, or made them smile. It produced a sensual, somewhat escapist response that we will explore in more detail later when considering the kinds of interpretative strategies that can be used in responding to dance.

We also observed that dance training, even if in a different style, affected responses to virtuosity and technique. Alisha, a trained bharatanatyam dancer who watched an English National Ballet (ENB) performance of Giselle, ${ }^{12}$ was seeing ballet for the first time and was astounded by the pointe work: "another amazing thing was just how they'd move across the stage just on their toes and that's incredible." However, she made a connection between ballet technique and expression:

It looks like their limbs are always stretched out to the limits in all of their movements, like their arms are really stretched out, their legs are stretched out and I mean that's such a contrast to bharatanatyam because in bharatanatyam everything is in one confined space, all the movements, the legs and everything ... that's what made it so dramatic for me, along with the emotions.

As a dancer, Alisha's focus on the "stretching out" of the dancers' bodies was based on comparison with her own experience of performing bharatanatyam and led into an emotionally engaged response.

Another point where we felt admiration of virtuosity related to a different kind of response was on the various occasions when individuals described their admiration in terms of their own inability to do the movements. As Nancy, an intermediate spectator of ballet, said: "I'm always in awe with classical ballet ... it's always, oh she can do this stuff and I will never do this stuff." In simple terms this represents a reversal of the clichéd response to modern art, "I could do that myself" (or its variant, "my four-year-old could do better"). In contrast, here the impossibility of the spectator doing the movement 
automatically invests it with innate value. However, there are also other implications here about projection of the self onto the other, which will be discussed in the following section on imagining moving and inner mimicry.

\section{Imagining Moving and Inner Mimicry}

Many participants derived enjoyment from bridging the gap between themselves and the dancer by imagining themselves dancing. In response to various styles of dance and from participants with different levels of experience, we received comments along the lines of "I was imagining doing it myself" or "I wanted to do it myself." For example, Moira, who had intermediate experience as a dance spectator, said: "You can put yourself there like you can think in your head that, replace her with yourself and that's me spinning around." Or Maureen, a retired teacher who had some dance training and taught dance as part of the primary school curriculum, said: "I just wanted to get up and move with them ... I love movement and as soon as you put something on I can move to it." Or Rosemary, in response to ballet: "I'm doing it, I'm doing it. I can feel it in my muscles ... if she lifts, I feel I want, you know ... I'm just with it."

These explicit and sometimes extremely passionately expressed responses are striking. They immediately recall Martin's concepts of "inner mimicry," kinesthetic sympathy," and "metakinesis" and Lipps's related argument that inner mimicry (innere Nachabmung) gave spectators the feeling that their experience of perception was taking place through the object or person perceived (see discussion in Reynolds 2007). Aspects of this are certainly present in the above examples, with subtle shifts according to whether the spectator is imagining that it is them doing the movements or that they are the dancer. The differences between these are subtle but significant and are worth drawing out in more detail.

In many instances of spectators' articulating that they were imagining doing the movement themselves, the reports were immediately followed by recognition that it would be impossible. For example, Nathalie, who was interviewed after the ballet performance in Glasgow, said that the performance "makes me want to dance, but I know I couldn't do that, sadly, those days have long gone." Or Tony, who had never been to a ballet performance before, said, "I appreciated the fact that somebody's putting in a lot of hard work to be able to do something like that, with their being able to twist their body into shapes that I couldn't imagine twisting mine into." Remarks such as these suggest that a sense of being unable to execute dance movements can be pleasurable and exciting for spectators. An experienced spectator whom we interviewed commented that "I think for, for most people watching ballet what you want to see is stuff you couldn't do yourself," with admiration of the virtuosity and technique being part of the response to the performance.

Another example of this was Justyna, also new to ballet performances, who said that she was impressed by the "twirls" because "they were perfect and I'm pretty certain that I wouldn't be able to do that so if you see someone do it, I feel like, wow." The "wow" factor also frequently provoked unfavorable physical comparisons between the spectator and the dancer. ${ }^{13}$ 
Rajni, an experienced spectator of bharatanatyam without significant dance training and who had never been to a live ballet performance before, was amazed by the technical prowess she observed during Birmingham Royal Ballet's (BRB) performance of Giselle, ${ }^{14}$ which focused her attention on speculating whether she could do it herself:

I was thrilled by seeing someone dancing, doing all these movements with standing on their toes, and, to be honest, I was more in awe [of] the way they were balancing and the grace of the dancer rather than what the storyline ... Seeing them dance on their toes and things, you feel like, can your legs do it, will you be able to do it, and that kind of feeling, probably in your legs as well, and that's how I felt ... can I do it? Can I balance my whole body on my toes? Can I do this when I jump?

Similarly, Bita, an inexperienced dance spectator, commented after watching ballet that she had been mainly watching the performer's feet and wondering if she could do it herself: "I would try but I don't think I can. It's my age and my weight and everything you know, you have to be slim and younger to try that. I was thinking you know if I can stand on my toes, but I don't think I can." For some participants the response to this challenge of imagining doing movement that they knew would be impossible was to step out of their own body and either invest themselves into that of the dancer or else, as John suggests here, construct an out of body experience:

The experience that I get when watching real fine dance, is almost more of an out of body experience. I feel that I'm leaving behind the limitations of my own clumsy and graceless body, I'm somehow viewing it from above so I tend not to think of my own body at times because the comparison would just be too ... laughable.

Another participant made a similar, although differently phrased, suggestion:

Pina: Well, so this is going to sound strange but you know sometimes you can imagine yourself doing a dance or throwing a ball or whatever and then you do it and that doesn't have any real connection to what it is that you imagine, so it's almost like the imagined motion looks like someone else who knows what they're doing doing it, but my actual muscles don't ... so the movement in my head happens the way that one might assume, when watching someone else, but when I actually need to translate that action ... into an actual movement of my body that doesn't really come out.

In other words, Pina describes how in her imagination she is able to do things as if possessed with the skills, the strength, and the muscle knowledge that in reality she does not possess. This fantasized identification with an ideal other sometimes constitutes a significant source of pleasure for spectators of dance. Many contemporary dance practitioners actively set out to trouble such misrecognitions and to demystify the role of the dancer.

As this range of different responses indicates, imagining oneself as the person moving despite sitting still is a response closely linked to individuals' personal experiences of 
dance and related kinesthetic and emotional associations-including fitness, body image, and gender. It is also tied up with the observer's motor familiarity with the movement, as emphasized by the mirror neuron research referred to earlier. This was very apparent in interviews conducted with dancers and ex-dancers. Here some similar statements occur about imagining doing the movements, although with trained dancers the responses are more heightened and precise in their imagination of details and movements.

Fleur, an ex-professional contemporary dancer who was interviewed after the George Piper Dances (GPD) performance, said that when dance "works" for her "it's like one of the best things in the world because you feel, you know, you feel satisfied, you feel excited, I feel, inspired to dance again." Even if she does not literally feel like dancing, the pleasure derived from watching is closely related to the pleasure of doing: "obviously seeing dance doesn't necessarily make you want to get up and dance but it's that excitement, it's that enjoyment, it's that energetic kind of feeling."

Brangwen, an ex-professional ballet dancer who currently teaches ballet, commented after seeing the ENB's Giselle, a ballet in which she had performed the peasant pas de deux, that sometimes "it was like watching myself on a film inside my head while I'm watching them do it ... almost as if I was associated but at the same time dissociated-very hard to describe." Later she continued:

There were moments when I could almost see myself standing in the wings waiting for the next cue to go on, and seeing what I would see, if I was there doing it. And certainly remembering ... there's a bit where they go "da da da da" and then "da da da dee" and then they take an arabesque and then a jump and they do a little fouette and they do seven of them and I was going "one," and I knew, and I mean in my head, it was as if I was doing it, because I'd have to count it ... I was almost reliving it, going through the same thought processes as I would have done while I was doing it.

Doreen, a trained ballet dancer, said after watching ENB's Giselle that “Once you've danced, you'll never lose that, you'll always want to dance, always, mostly when you're watching it I think, it's the fact that you want to: 'I wish I could do that again,' 'I wish I was doing that again." The "I wish I could do that again" and the feeling of "reliving" the act of dancing articulated by participants with experience of dancing the style they were watching are, of course, qualitatively different from the "I wish I could do it" expressed by nondancers. In one case the trained dancers are consciously recalling and/or imaginatively replicating almost exactly the movements and memories of the performance. In the other there is more frequently hesitancy, self-consciousness, hope, and envy. Therefore, both dancers and nondancers experienced varying levels and kinds of inner mimicry, kinesthetic projection, and empathy/sympathy, where "sympathy" encompasses a more conscious, reflective response, such as comparison of the dancer's virtuosity or physique with one's own skill or figure. The extent and nature of these responses were hugely dependent on the individual subjectivity of the spectator rather than being wholly dictated by the characteristics of the performance. 


\section{Kinesthetic Responses and Music}

Not surprisingly, since kinesthesia involves interplay between different senses, responses to the combined impact of movement and music had a significant impact on the extent of kinesthetic experience. An experienced spectator who was interviewed about the ballet performance in Glasgow cited a memorable moment:

Georgia: I think at that exact moment there was also a kind of crescendo in the music so the two things came together and there was a rush of excitement, that she was doing something difficult and she was doing it very well, the music was dramatic and the combination of that was, was an exciting little moment.

Musical background and taste can set spectators' expectations. Marianne, who came to the GPD performance, had never seen live dance before, but she is a musician who has played cello:

Like I say, the music for me, in the middle two ["Propellor" and "Edox"], really worked, I'm a bit of a sucker for strings anyway, and cello, so they were like, quite sort of cello, sort of baroque stuff weren't they, and I just found that worked, that sort of sparseness and precision of the baroque music, paralleled for me, what I was kind of wanting to see in that type of contemporary dance.

In several cases a positive response to the music appeared to facilitate a kinesthetically and/or emotionally empathetic response to the dance, while negative or indifferent reactions to the music were associated with less empathetic responses. For some participants the appeal of music was closely connected to mood, such as with Sophia in response to a bharatanatyam performance: "It's really rhythmic and jolly I'd say, very upbeat ... as I said, you almost wanted to tap your feet you know, to the rhythm of the dancer's performance. So just, yeah, cheerful and it kind of in an emotional sense conveyed this really ... it conveyed happiness in a way." Here the emotion-of unspecific happiness-is clearly connected to the mood and tempo of the music and the rhythmic response that prompts in the body. For Sophia this was tapping her feet, for other participants it was nodding their heads to the music or following the rhythm with their fingers. Such kinesthetic responses are perhaps primarily in terms of the music rather than the movement, although inevitably the two become very closely entangled.

This was the case for Penny, a keen ballet spectator and lover of classical ballet music, for whom music played a crucial role in her response to the Glasgow ballet performance, making her feel that she wanted to "go up" with the ballerina and with the music: "I think she sort of did pirouettes, not quite proper pirouettes, it was more like pirouetted turns, and I felt sort of sweat with her, and especially the way the music goes up, you really feel you just want to go with her, that was nice." Similarly, for Maureen, also an experienced ballet spectator, correlating music with facial expression was an important part of how she related to the ballet piece: "I was just watching and found that I was able to under- 
stand what she was doing, I was looking at the way she was using her body and her facial movements and how her face was interpreting the music if you like, the dance, as well as just her body." She attributed her enjoyment of the performance to the music as well as the dance: "I liked to look at it, it's a nice thing to see and I suppose it wasn't just a dance it was the music that came with it that gives me that feeling." Conversely, she related her lack of engagement with the bharatanatyam to the negative effects of the music: "I couldn't concentrate as easily as I could on the previous two and I was very aware of the music. The music seemed to be an insistent ... beat, I don't know if that's the right word, which I didn't like."

Rajni, an experienced spectator of bharatanatyam, attended an evening of bharatanatyam performances by Upasana ${ }^{15}$ and a performance of BRB's Giselle. The music for the bharatanatyam piece, which she related to easily, facilitated an emotional response.

It sounded like the main part of the music was based on like, the beats of the drums, the particular type of drums that they played and it was, the voice, also, was very expressive, in the way, the way the words were said, were very similar to what the emotions were, the expressions that were brought by the dancers as well, so it kind of, it enhanced the feeling of what I felt, because the music that went with the dance, also played an important part too and it made me feel the same way as what they wanted me to.

By contrast, the ballet music made little impact on Rajni, and here she was attracted to the technical rather than the emotional aspect: "The music in general was a melody, to begin with at least. The second half was a bit different. What I mean is, it didn't excite me." Clearly many aspects of these responses, although they may feel spontaneous to the viewers, were predicated to large degree on cultural knowledge or "habitus."16

\section{Empathy as Embodied Anticipation}

Several participants reported embodied responses linked with sensations and feelings of anticipation and suspense produced by choreographical progression and development. Fleur described her response to what she called "abstract dance," which "doesn't have to have that narrative saying to me what it is":

Emotionally you go [makes gasping noise] you know what I mean, you can breathe with it, your heart can race with it, your eyes can go wider with it, it's hard to explain, but you know when it happens, you know when you're engaged with it, you know when it's communicating with you and when actually the energy, or the sensitivity or the planning of it or something that's so precise that that's what you focus in on, and you home in on.

Fleur's repeated use of the phrases "with it" and "with you" underlines her experience of connecting her body rhythms (breathing, heartbeat) and emotions with the dynamics of the dance. One of the pieces in the GPD program was Russell Maliphant's Broken Fall, and some participants commented here on the effects of suspense in the choreography, which 
drew them in and produced an embodied sense of anticipation. Matthew, an experienced spectator of contemporary dance, referred to the dance's intensity, momentum, and "a kind of inevitable drive" that "drew you in." He emphasized the importance of pacing: "I think it was meant to be a slow build up on the viewer ... it was meant to have that sense of becoming more and more and more and more immersing, that's certainly the way I see it." Matthew saw the piece as building up to a climax in the final, very dramatic fall, but he felt that the very slow build-up was the main focus. The dance gave him "that sense of being on the edge of, on the edge of something but that edge was constantly pushed forward the whole time." He embodied this suspense in altered breathing patterns and muscular tension.

Interviewer: How did it make you feel?

Matthew: I suppose slightly breathless and tends to respond in your breathing I suppose in a way, that echoes the movement, so, as the position, line is held, you tend to kind of hold yourself as well in that respect, waiting for the next thing to happen almost if you like. It's a sense of anticipation, a sense of expectation, I'm trying to think of words to describe that sense of slightly being suspended but with quite a degree of physical, emotional tautness, not tension, tension's the wrong word 'cuz it suggests stress, but tautness, but with a very, a very kind of breathlessly excited...

Sonia, a spectator with substantial experience, also focused on embodied response to choreographed tension and progression.

I liked the way that the falls became more and more dramatic as it passed and they built up to the final fall which is almost heart-stopping isn't it? And you realise, part of me, this is nothing to do with it, I was thinking, "they wouldn't be able to do that if it was me," 'cuz she's such a tiny little thing, you could throw her around couldn't you? But also, what a tremendous amount of trust she must have in them, because, you know, really was quite high wasn't it some of them ...

Sonia was also affected in her breathing:

Interviewer: And when you said it was "heart-stopping" what do you think, can you remember what you were experiencing at the time?

Sonia: It's just a deep intake of breath, because, you know, I mean, as I say, I'd seen it before, and I didn't really think she was going to fall but it just, you know, she does have to trust them.

Effects of embodied anticipation can be heightened by music. Sonia commented that the music in Broken Fall "built up to a crescendo for the final fall, so I really enjoyed that one." She described it as "beating" and "like a heartbeat": "Well I thought it did, at the heartbeat, when, because, I thought the heartbeat, and then it went, it built up, and it got louder and louder and stronger and stronger and stronger until the final fall ... I think it added to the adrenalin, the heart-stopping, yes, that emotion, yeah."

The embodied responses experienced by both Matthew and Sonia, involving almost 
automatic/instinctive anticipation of falling, with altered breathing and muscular tension, can be described as "empathetic" and involve "contagion." Sonia's response also involves "sympathy," where there is a more conscious construction of a similar point of view, as well as an awareness of difference ("they wouldn't be able to do that if it was me"). Sonia speculated about the degree of trust the dancer must have in her partners, and was very aware of what it must be like as a woman to depend on male dancers. "It seems such a, almost dangerous thing to do, doesn't it? You can't think of many people who would actually put themselves in that position, especially with two men."

Choreographical structure frames temporality and progression and plays a crucial role in shaping anticipation, which produced in these spectators what neurophysiologist Alain Berthoz calls "anticipatory postural synergies" (Berthoz 2000, 225) or what Merleau-Ponty describes as "a certain potential for action within the framework of the anatomical apparatus" (Merleau-Ponty 1962, I09). This embodied anticipation can involve changes in the postural condition of the muscles without actual movement taking place. ${ }^{17}$ Such changes were cited by Martin as a feature of "inner mimicry"; embodied anticipation is similar to Martin's idea in this respect, but it is also different in that the sensations and feelings it involves arise out of connections between the dance and the spectator and are not limited to being an "imitation" of the dancer that purportedly gives access to their feelings.

\section{Sensual and Escapist Motivations in Watching Dance}

The concept of interpretative strategies suggests that when engaging with dance, individuals are motivated by the hopes, rewards, and pleasures they want to find within a work. For example, while some spectators derived pleasure from a sense of closeness and awareness of the dancers' physicality and effort, for others it was more pleasurable to seek an escape and suspension from reality. One notable thread we found in participants' response to ballet performances was how the perceived effortlessness and beauty of the movement made some spectators "feel good."This was the response found among a particular group of participants for whom the gratification of watching ballet was that produced by the perfect, effortless character of the movement and manifested in a warm emotional response - other expressions included that it "gladdens the heart," it "calms you down, relaxes you," it made the spectator "feel happy." For these participants the valued characteristic of ballet was the pleasuring effect it had on them. May, an experience ballet watcher, discusses this:

May: Just the whole thing just, was just ... lovely.

Interviewer: Is that a feeling you, you have when you watch ballet?

May: When I watch ballet, yes. Yes.

Interviewer: So you've said mesmerizing and you've said graceful, what other words would you use to describe it?

May: I was smiling all the time. I was happy to watch her.

Interviewer: What do you think it is about it that makes you happy?

May: The gracefulness or the beauty of the whole thing. 
These positive, happy, "glad" feelings provoked by watching ballet were not the only responses, but they were certainly among the most frequently recurring-particularly from women who were frequent ballet audience members. For participants such as Rosemary, who described how "ballet takes you completely out of yourself," this was clearly a significant motivation for them.

These are motivations and expectations that some participants attached to a particular form of dance movement - the instinctive and largely automatic processes that individuals employ when responding to the movement. It is problematic to claim that these feelings and emotions are a priori present in the movement itself. Instead, we might suggest that the emotional responses are projected onto the movement by the spectators. This is a debate similar to that which Thomas Clifton explores in Music as Heard when he discusses how the sensory properties we attribute to music in fact reflect our embodied experience of listening to it. For example, "The sound produced by an oboe is usually described as somewhat thin, nasal, rough, and slightly hollow. But this is not altogether accurate. Rather, these words are descriptive of our bodily behaviour: we have adopted an attitude of hollowness, thinness etc." (Clifton 1983,68 ). Clifton also presents other examples: we say sky blue is restful because our body has adopted a mode of restfulness, we say a movie is edgy because our body has adopted a mode of edginess, we say music is bouncy ... and so on. These, Clifton argues, are not descriptions of stimuli impinging on the body but of effects produced by the body, without which the responses would not exist.

This certainly seems to be the case in the following response, where Sophia is asked how it made her feel to watch the dancer balancing on one foot: "I don't know, just peaceful, it's just because the movements that convey balance, maybe make you empathize with the ... this kind of idea of balance ... just the balance of being and the kind of balance of, of feeling. Applying this to the world around you." Clifton's approach is similar in some respects to Martin's, which was strongly influenced by Theodor Lipps's theory of Einfublung and his connection of empathy and kinesthesia in aesthetic experience. Both Lipps and Martin discussed empathetic response even to inanimate objects, and Martin emphasized the kinesthetic nature of this response. The object could be experienced in kinesthetic terms, as a kind of replica of the spectator's body and its movements. For example, this could happen in response to architecture, where "the building becomes for a moment a kind of replica of ourselves and we feel any undue strains as if they were in our own bodies" (Martin 1939,48 ). The receiver's embodied experience became bound up with and objectified in his/her perception of the work. "If we really want to 'find' a Beethoven symphony we must hear it as our own voice with its emotional cadences and timbres, its breath phase, pulse beat and body rhythms" (Martin 1939, 5I). In a sense, we experience the music as an extension of our own bodies, and we attribute to it the sensations and associations it arouses in us. Martin wrote that "Psychologists have discovered changes in the postural condition of the muscles in response even to shapes, though there is no outward movement of any kind visible" (Martin 1939, 47). He cited Lipps's example of motor response to an architectural column and related this to personification, "this frank interpretation of external things in terms of personal reactions (Martin $1936 / \mathrm{Ig} 68$, II9-20). Moving this debate to the context of dance, we can see how the restful, calming, gladdening responses 
to ballet are effects produced by the body and projected back onto the movement. Clearly, there is something about the quality of these movements that provokes these particular responses, something that we might locate in the flow or elegance of the movement, but the response itself is constructed through the embodied process of engagement rather than (as Martin claimed) through direct access to the dancer's feelings.

It is revealing also to explore responses that discomfit spectators. For example, one discussion group was held after a performance of The Porcelain Project by Needcompany at the Tramway in Glasgow. ${ }^{18}$ As one participant immediately noted, "I think in classical ballet you're used to people making beautiful gestures and there's lots of unbeautiful gestures in this."These "unbeautiful" gestures produced responses of feeling uncomfortable, disturbed, and unhappy. Interestingly, while spectators watching ballet were comfortable with articulating how graceful or elegant movements made them feel glad or uplifted, the emotional responses produced by these "unbeautiful" movements were harder to articulate, as if the spectators were seeking to keep them at a distance rather than internalize them. Indeed, at times they found it difficult to even speak of those emotions, as suggested in this exchange between participants:

Mark: It just sort of sucked you in and took you somewhere that you didn't think you were going to go, and to do that with physical movement and very little ...

Karen: I agree. It was just so powerful that you felt those things, and it was just so powerful that you felt ... those things.

Audiences' emotional responses to dance movement, therefore, are produced by the process of engaging with the work rather than elements found within the work alone. In other words, spectators' responses to movement are not produced in a singular manner by the movement alone-a particular quality of movement always producing a particular kind of response-but also by the interpretative strategies with which individual spectators engage with that movement.

This became very clear in discussion groups held after a performance of Double Points: $3 x$, a contemporary piece that was choreographed specifically for the Watching Dance project by Rosie Kay and based on an earlier piece by Emio Greco. The performance consciously experimented with different sound scores and a set amount of physical language to explore the effects of sound on perception of movement. In some sections of Double Points: $3 x$, the very audible (though not amplified), rhythmically patterned breathing of the dancers was used as a "soundscape" instead of music. Other sections used classical and electroacoustic music.

In the discussion groups that took place with audience members after the performance, it quickly emerged that participants engaged differently with the same movements when experienced in the context of different soundscapes. For example, some participants particularly responded to the "breathing" segment of the performance, for the visceral sensation of sweat, effort, and strength that it communicated to them. Other disliked this section, saying that it made them feel uncomfortable, and preferred the more relaxing and unified feeling created when the dancing was accompanied by music. Differences in preferences and tastes are unsurprising-and there were positions taken at every point 
between these two extremes-but what is interesting is that here it becomes possible to identify two distinct "interpretative strategies" with which audience members approach dance. To explore this further we shall use two particular spectators, Don and Nicole, who present these different approaches clearly.

Don, in his fifties, is a moderately experienced dance spectator with a preference for what he terms "modern dance." His response to all aspects of the performance was fairly visceral, with comments including that he loved watching "the beads of sweat thrown off the forehead as they turned round"; that he loved the intensity of the silence because "you can see the hard work, you can feel the hard work that's gone on there"; and that "I looked at the leg muscles with that on and I kept seeing the rawness and that bare skin there and the muscle tones and you can see that in close up like you know I really admired that in both the male and female, it's really sound." Don's responses were particularly strongly expressed, but his preference for the silent section-and his reasons for thiswere shared with other participants. Marcia, for example, similarly found the breathing section the most engaging: "I could hear the breathing and the movements, the hitting the floor I liked that ... The sounds. Perceiving the sounds made the show more real, and I think it underlined the humanity of the dance."

In contrast Nicole-an experienced spectator of a range of dance styles-had the opposite response, which may result from a different interpretative strategy. For Nicole the breathing section made her feel "uncomfortable," saying that "when there was no music, I found that it was too intimate. I felt too close. I didn't want to feel like that." In response to Don's interest in the sweat and effort of the dance, she commented: "Do you actually need to see the hard work? I mean for me, I think that life itself is so hard and everybody is working really hard, do we actually, when we come and see art, do we need to see all the sweat and the tears and the exertion ..." Finally, she commented on why she preferred the sections of the performance with music: "I want to see that immersion in music, that that place where music and dance where there is no end, there's no break between the two." For Nicole the music almost provided a kind of shroud over the effort (the humanness?) of the performers and instead allowed her to watch the movement as effortless, perfect, ethereal.

Other participants had similar responses; Jules and Luke, for example, echoed Nicole's expression of "relief" when the music restarted after the breathing session, and several participants described the classic music section as "relaxing." Luke, who had never been to see a dance performance before, felt that music was necessary for the performance to come across as "dance":

There was a very drastic contrast there when the classical music came in because it was you know, a relaxing part of the dance even though the movements of the dancers were probably similar the change there was so striking. To me that's really when the dance began if you like, when the classical music started because obviously you have for me I had this feeling that oh now the music's become something more, more easier to take in this is when the dance has really begun. 
While Jules commented that: "Yeah I felt much more stimulated when the music started again whereas before I could feel myself kind of [makes clicking noise] I don't know becoming disengaged I guess with the performers." Clearly the breathing section had a tendency to make some people uncomfortable, and therefore be something they did not like, although at the same time this could be described as an indication of its impact. Sarah, for example, wrote that "The breathing soundtrack made me feel uncomfortable and conscious of my own breathing and also more aware of the dancers as people and bodies." The degree of closeness was unwelcome for some spectators, with Mark noting "A feeling of tension existed which made me feel rather un-relaxed-almost the audience became part of the dance experience due to the close proximity."

As with all research engaging with the multiple and many-faceted nature of audience responses, the situation is complex. However, we feel there are two clearly defined interpretative motivations here. For one group of participants-schematically exemplified by Don-engagement and empathy are produced by intimacy and intensity, which in this instance were enhanced in the breathing section. This group seeks out rawness and sensuality in its dance encounters. For another group of participants-exemplified by Nicole-it seems that a degree of distance, facilitated by the music, is necessary for a kind of empathetic engagement, which involves a suspension of reality. These spectators seek out a kind of release or relaxing escapism in dance. While these were the most striking motivations amongst the participants in question, we recognize that there is a wide spectrum of possibilities and that motivations are in large part shaped by the cultural contexts and dance traditions with which spectators are familiar.

It is worth noting here that while some individuals respond to dance through the lens of their own particular interpretative strategy, others are happy to adopt different viewing positions according to what they are watching. For example, when watching a mixed bill of performances by the Scottish Ballet, one participant noted that while with one piece of choreography he had been happy to "sit back and let it wash" over him, with a different piece of work choreographed by Trisha Brown he had felt driven by an imperative to ask "what does this one mean?"19 While some participants consciously or unconsciously adjust their interpretative strategies to different performances, others found this more challenging, exhibiting strong attachments to particular desires and pleasures and demonstrating greater disappointment when these were not fulfilled.

Making connections between the various elements of our research, we feel that Don's and Nicole's responses each exemplified these contrasting interpretative or viewing strategies. These then influence not only what individuals find and respond to in the performances they see but also, naturally, what kind of dance they attend. Broadly speaking, the desire for distance and escapism was identified as a significant motivation among the frequent classical ballet spectators who participated in the research. In contrast, the desire for a visceral response to intimacy and intensity was a different kind of approach that was adopted by some in terms of all dance (including ballet) but was more frequently evident for certain kinds of contemporary dance. ${ }^{20}$ 


\section{Conclusion}

When dealing with qualitative audience research, the richness and complexity of the material presents great opportunities and challenges. In presenting the participants' responses and perspectives, we are aware that there is as much we have left unsaid and unexplored as we have been able to analyze in detail. The insights this material could add to the relationship between audiences, gender, and dance-or between class, education, and reception-could each merit a paper in their own right. Here, however, we have attempted to map out a variety of kinesthetic pleasures that individuals and groups of spectators seek out in the dance performances they watch; to engage with some spectators' comments in detail; and to explore the role of kinesthesia and empathy in the pleasures they reported. These included enjoyment of the "wow" factor that virtuosic dance affords; the pleasure of imagining dancing oneself and the problem of investing the self into the body of the other; sensual responses that engage with the effort, the strength, and the sweat of dance; escapist responses that relish the gladdening and up-lifting feeling of graceful movements; multisensory responses that seek concord or discord across stimuli; and embodied responses where the spectator's breathing, posture, and energy are altered by the process of watching.

This variety of attitudes suggests that kinesthetic responses are a key source of pleasure and motivation for many dance spectators. When considering these kinesthetic responses, we feel it is useful to return to the different, nonhierarchical, but inevitably overlapping, concepts of empathy, sympathy, and contagion as a valuable method of describing nuanced distinctions between the various kinds of engagement. Experiences of embodied and imaginative connection between the self and the other, particularly in moments of inner mimicry or imagined substitution, can be considered in terms of kinesthetic "empathy." Responses that are cognitive and reflective-such as admiration for the virtuosity of others, appreciation of effort or the projection of emotional intention onto movementmight be considered in terms of kinesthetic "sympathy." Connected to both of these is a kind of kinesthetic "contagion" between spectator and audience. This might describe those instances where spectators passionately describe the feeling of joyful pleasure in uplifting and graceful movement, where the spectator responds to the dance in an immediate emotional manner. It might also describe the process where audiences find their heartbeats and breathing moving into synchrony with their perception of the movement, possibly also involving auditory perception, particularly of music or dancers' breathing.

The significance of what audiences bring to the viewing experience means that the concept of kinesthetic empathy/sympathy is more fruitful when wrested away from intentionalist models and located instead in the relationship between the viewer and the dance. Also, in order to avoid essentializing "dance" and universalizing the dance audience, it is important to pay attention to the specificities of different styles of dance. Although it is true that different styles and vocabularies can coexist even in one piece, and that there are some spectators who respond kinesthetically to a variety of danced genres, we found that many people do have distinct preferences. Rather than universalize such responses, we explored their links with cultural competence, experience, and motivation and pleasure strategies. 
Across this range of responses, what we are witnessing is spectators articulating the effects on their own body, imagination, and feelings that result from watching the movement of others. Across this spectrum we argue that the kinesthetic experience needs to be considered through the question of pleasure. Whether sympathetic, empathetic, or contagious, the kinesthetic experience can be described as an affect. We need to consider the impact of this upon the audience, reflecting on what they do with it and how they respond to it within their lived experience of dance. What spectators feel and why is highly individual and is linked with wider social, cultural, and lived experience. As in the words of Martin Barker cited above, "audiences bring their social and personal histories with them" (Barker 2006, 124), and we have seen the importance of motivation and taste in influencing response. The consideration of pleasure alongside that of kinesthesia allows us to recognize that for one spectator the empathetic response might be to allow themselves to be bodily carried away by an escapist flow of movement, while for another it is to feel viscerally involved in an awareness of effort, muscle, and sinew. Consideration of pleasure similarly allows us to recognize different desired self/other relations between spectator and dancer(s), which ranged from pleasure in intimacy and closeness to discomfort and displeasure in proximity and desire for aesthetic distance, including distance from one's own (imperfect) self.

\section{Notes}

r. Recent studies of "mirror neurons"- circuits in the brain that are activated both when performing an action and when observing the actions of others-have looked at the behavior of dancers when watching dance. They indicate that motor familiarity with the movement being watched seems to be the key factor in activation of the mirror neuron system, and also that mirror system activity depends on possessing the motor representation for an observed action and cannot be based on visual knowledge alone. See Calvo-Merino et al. (2005 and 2006). Susan Foster has welcomed this emphasis on the role of specific expertise and training, which she sees as "in keeping with" Alain Berthoz's emphasis on culturally specific perception of movement (Foster 2008).

2. It is worth acknowledging here that the bow of the cognitive processes that occur while audiences are watching a performance is largely out of reach to audience research that by definition takes place after the event. In some sense, therefore, the primary experience is available only through the refraction of conscious reflection. However, such reflection not only precedes, informs, and motivates future experiences but may also form a valid and vital element of the lived experience of performance in the moment.

3. This exercise was designed to allow as close comparison as possible between the neuroscience and audience research elements of the Watching Dance project as a whole. However, we recognize that direct comparisons are not always possible.

4. This possibility is not something explored in this paper. However, a further stage of the Watching Dance project will be to take the themes discovered and explored qualitatively in this discussion and develop a questionnaire that will enable a parallel quantitative analysis.

5. Note that Martin associates "inner mimicry" with active response, whereas Bertolt Brecht famously argued that empathy rendered spectators passive and uncritical.

6. For instance, his voice can be heard clearly in the words of dance scholar Judith Lynne Hanna, writing in 1983: "Kinesthetic sympathy occurs when we see in a human body movement 
that we experience vicariously in our nerves and muscles; the movement evokes associations we would have had if the original movement had been ours" (qtd. in Lambert 2002, 46).

7. Moreover, this specificity includes differences, which are bound up with power structures and struggles. For this reason, Mark Franko, writing on American dance in the 1930s, distinguished between "affect" and "emotion" in choreography, where "affect" was aligned with universalism, abstraction, and essence, while "emotion" was historically and socially specific. "The perception of movement as emotional or affective was indispensable to the audience's recognition of its revolutionary or bourgeois qualities" (Franko 2002, 57).

8. These were performed live to participants in Glasgow in February 2009. Participants watched short pieces (four minutes) of ballet and bharatanatyam. Each sequence contained elements of narrative, and these specific styles were selected for their distinctiveness and relatively highly codified form. The spectators watched the performances in an intimate studio context, in pairs, while also participating in TMS (transcranial magnetic stimulation) investigation of motor cortex activity. The setting and context, therefore, were somewhat unusual, particularly in terms of the closeness or intimacy of the performances. The ballet sequence was choreographed by Corinne Jola in consultation with dance scholar Seon Hee Jang from Sejong University, Korea. It was a concatenation of three fairy solos from the Royal Ballet version of Sleeping Beauty— "Breadcrumb Fairy," Enchanted Garden," and "Lilac Fairy"-and one mime part from "Lilac Fairy."The music was recorded extracts from Sleeping Beauty-Ballet in a prologue and three acts from Tchaikovsky Op. 66 (2007). The bharatanatyam piece was a popular "padam" from the traditional repertoire describing God Krishna's childhood pranks. It was a mime piece set to a three-beat cycle. The music was "Theeradha Vilayattu Pillai" by Subramanya Bharathiyar, taken from "Nupura Naadam." The ballet was performed by a twenty-four-year-old female Caucasian professional dancer. The bharatanatyam was choreographed and performed by a twenty-nine-year-old female Asian professional bharatanatyam dancer. For a clip of each performance, see $<\mathrm{http}: / /$ www.watchingdance. org/research>.

9. They also both have a strong narrative tradition, but the impact of storytelling on response to movement was not a question we addressed in this part of our research.

Io. On this point Martin Barker suggests that rather than using categorizations of experience according to absolute frequency of attendance, it would be more appropriate to use self-definitions (such as "as often as possible" or "seldom" or "never") as availability and opportunity impact attendance. Such definitions imply an attitude to a danced genre irrespective of the number of actual occasions a person attends a dance performance (personal communication, February 20Io).

II. All participants' names have been changed in this paper.

12. Performed by the English National Ballet (production and additional choreography by Mary Skeaping) at the Palace Theatre in Manchester, September 23-27, 2010.

13. Reports of admiration and indeed envy of the abilities and physicality of the dancers was a relatively common occurrence, particularly between the female participants and female interviewer, as in this exchange:

Interviewer: So how, how did that make you feel seeing those, er types of, er ....

Samantha: Bit jealous. Very jealous and wanting to go on a diet. Um, yeah it, it was sort of ... it was kind of, not that I didn't enjoy the dance but I think I was admiring her as a dancer more than necessarily like enjoying it ... I was sort of amazed by her and what she could do rather than understanding the story or being drawn into it in that way.

I4. Performed by the Birmingham Royal Ballet (produced by John Bintley and Galina Samsova, additional choreography John Bintley) at the Lowry, Salford, July 8-I2, 2008.

15. Members of the Upasana group (Vaishnavi and Nivedita Ganesh) performed "Bho Shambho," "Thillana," and "Nama Shivaya" at the Lal Quila Restaurant, as part of the program of the 
Twentieth European Conference on Modern South Asian Studies (ECMSAS), which was held in Manchester on July 8-II, 2008.

16. This is consistent with McConachie's (2008) point about empathy potentially being experienced as spontaneous while also being dependent on prior cultural knowledge.

17. See also Hagendoorn (2004 and 2010) and Foster (2008).

18. The Porcelain Project, Needcompany, choreographed by Grace Ellen Barkley. Performed in Tramway, Glasgow, October 2008.

I9. The two pieces were Ride the Beast, choreographed by Stephen Petronio; and For M. G.: The Movie, choreographed by Trisha Brown. Performed by the Scottish Ballet, Theatre Royal, Glasgow, September 2008.

20. Inevitably such differences are not absolute. We also came across a number of participants for whom the attraction of ballet was its sensuality, physicality, and indeed sex appeal. This included Carolyn, who made the following comment: "I have to say that as far as I'm concerned the sweat is really important because eh, I think it's I find dance particularly ballet, all all dance but ballet in particular eh, it is a very physical and very sexy thing. And when you [see] Carlos Acosta wearing next to nothing [laughter] sweating it is pure sex it is really really powerful. It's it's that what it's supposed to be, for me, you know it is it is sex on stage if you like it's such a physical presence and I find that very you know I find that terrific."

\section{Works Cited}

Barker, Martin. 2006. "I Have Seen the Future and It Is Not Here Yet ...; or, on Being Ambitious for Audience Research." Communication Review 9 (2): 123-4I.

Berthoz, Alain. 2000. The Brain's Sense of Movement. London: Harvard University Press.

Bourdieu, Pierre. 1984. Distinction: A Social Critique of the Judgement of Taste. Translated by Richard Nice. London: Routledge.

Calvo-Merino, Beatriz, Corinne Jola, Daniel Glaser, and Patrick Haggard. 2008. "Towards a Sensorimotor Aesthetics of Performing Art." Consciousness and Cognition 17: 9II-22.

Calvo-Merino, Beatriz, Julie Grèzes, Daniel Glaser, Richard Passingham, and Patrick Haggard. 2006. "Seeing or Doing? Influence of Visual and Motor Familiarity in Action Observation." Current Biology 16 (r9): 1905-Io.

Calvo-Merino, Beatriz, Julie Grèzes, Richard Passingham, and Patrick Haggard. 2005. "Action Observation and Acquired Motor Skills: An AMRI Study with Expert Dancers." Cerebral Cortex 15: 1243-49.

Clifton, Thomas. 1983. Music as Heard: A Study in Applied Phenomenology. New Haven, CT: Yale University Press.

Daly, Ann. 1992. "Dance History and Feminist Theory: Reconsidering Isadora Duncan and the Male Gaze." In Gender in Performance: The Presentation of Difference in the Performing Arts, edited by Laurence Senelick, 239-59. Hanover, NH: Tufts University/University Press of New England.

Foster, Susan. 2008. "Movement's Contagion: The Kinesthetic Impact of Performance." In The Cambridge Companion to Performance Studies, edited by Tracy C. Davis, 46-59. Cambridge: Cambridge University Press.

Foster, Susan. 2010. "Dancing with the 'Mind's Muscles': A Brief History of Kinesthesia and Empathy." Keynote address, presented at the conference Kinesthetic Empathy: Concepts and Contexts, University of Manchester, April 2010 (available at <http://www.watchingdance. ning.com $>$ ).

Franko, Mark. 2002. The Work of Dance: Labor, Movement and Identity in the I930s. Middletown, CT: Wesleyan University Press. 
Gallese, Victor. 2008. "Empathy, Embodied Simulation, and the Brain: Commentary on Aragno and Zepf/Hartmann." Journal of the American Psychoanalytic Association 56: 769-81.

Geraghty, Christine. 1998. "Audiences and 'Ethnography': Questions of Practice." In The Television Studies Book, edited by Christine Geraghty and David Lusted, I4I-57. London: Arnold.

Gibson, James Jerome. 1979. The Ecological Approach to Visual Perception. Boston: Houghton Mifflin.

Gould, Glenn. 1984. The Glenn Gould Reader. Edited by Tim Page. London: Butler and Tanner Ltd.

Hagendoorn, Ivar. 2004. "Some Speculative Hypotheses about the Nature and Perception of Dance and Choreography." Journal of Consciousness Studies in (3-4): 79-IIO.

- Forthcoming. "Dance, Choreography and the Brain." In Art and the Senses, edited by D. Melcher and F. Bacci, 499-514. Oxford: Oxford University Press.

Järvinen, Hanna. 2007. "Some Steps Towards a Historical Epistemology of Corporeality." In Society of Dance History Scholars, zoth Annual Conference Co-sponsored with CORD, 145-48. Paris: Centre national de la danse.

Lambert, Carrie. 2002. "On Being Moved: Rainer and the Aesthetics of Empathy." In Yvonne Rainer: Radical Juxtapositions 196I-2002, edited by S. Sachs, 41-64. Philadelphia, PA: University of the Arts.

Martin, John. 1933. The Modern Dance. New York: A. S. Barnes.

- 1936/1968. America Dancing: The Background and Personalities of the Modern Dance. New York: Dance Horizons.

- 1939. Introduction to the Dance. New York: Dance Horizons.

- I963. John Martin's Book of the Dance. New York: Tudor.

McConachie, Bruce. 2008. Engaging Audiences: A Cognitive Approach to Spectating in the Theatre. New York: Palgrave Macmillan.

Merleau-Ponty, Maurice. 1962. Phenomenology of Perception. London: Routledge and Kegan Paul.

Oxford Dictionary of English (OED). 2003. Edited by C. Soanes and A. Stevenson. 2nd ed. Oxford: Oxford University Press.

Reason, Matthew. 2006. "Young Audience and Live Theatre, Part r: Methods, Participation and Memory in Audience Research." Studies in Theatre and Performance 26 (2): 129-45.

Reynolds, Dee. 2007. Rhythmic Subjects: Uses of Energy in the Dances of Mary Wigman, Martha Graham and Merce Cunningham. Alton: Dance Books.

Sauter, Willmar. 2000. The Theatrical Event: Dynamics of Performance and Perception. Iowa City: University of Iowa Press.

Schoenmakers, Henri. 1990. "The Spectator in the Leading Role: Developments in Reception and Audience Research within Theatre Studies." In New Directions in Theatre Research, edited by Willmar Sauter, 93-I06. Munksgaard: Nordic Theatre Studies.

Silverman, David. 1993. Interpreting Qualitative Data: Methods for Analysing Talk, Text and Interaction. London: Sage.

Stein, Edith. 1970. On the Problem of Empathy. The Hague: Martinus Nijhoff.

Titchener, Edward. 1909. Lectures on the Experimental Psychology of Thought Processes. New York: Macmillan. 